\title{
NATURALIZACIÓN Y RELATIVISMO EPISTEMOLÓGICOS
}

\author{
Julio C. ARMERO \\ UNED, Madrid
}

Hace más de veinte años un filósofo espaniol decía que la filosofía es el semáforo del saber. Tenemos creencias, opiniones, hacemos juicios, existen expertos que dictaminan sobre diferentes cuestiones, hay disciplinas que gozan de la aceptación de los ciudadanos. La tarea atribuida a la filosofía por esta concepción es decidir, entre estas propuestas, qué es conocimiento y qué no lo es. El cometido es excesivo y arrogante, según la mayoría de los filósofos. Sin embargo, una de sus ramas, la epistemología, pretende fundamentar el conocimiento, o al menos, ofrecer criterios de qué es conocimiento. En la segunda mitad de este siglo también esto se ha considerado excesivo, y muchos autores piensan que la epistemología no goza de ningún privilegio vedado a los demás saberes que le permita dictaminar, ni fundamentar ni dar criterios. $O$, como mucho, si puede seguir haciendo esto, tiene ella misma que basarse en esos otros saberes, de modo que no ofrece más seguridades que ellos. Cuando la epistemología se practica con esta cautela, se la practica, de acuerdo con estos filósofos, en su versión naturalizada.

"Naturalización", en el sentido que se le suele dar en filosoffa, es un anglicismo que se ha naturalizado bien en nuestra lengua. Esto es, hemos naturalizado la palabra con la imprecisión que muestra en inglés y con la que le hemos añadido generosamente. La variedad de sus significados y la vaguedad de algunos de ellos explican en parte las contrapuestas actitudes que suscita el proyecto de naturalización de la epistemología de Quine. A. Goldman, por ejemplo, encuentra excesivo el proyecto, mientras que C. Solís lo encuentra insuficiente. La diferencia se debe, en lo fundamental a lo que cada uno espera de la naturalización y, en particular, cuando ésta se emprende según las propuestas de Quine, que, a su vez, se prestan a varias interpretaciones o son varias y diferentes. 
En inglés unaturalizar» significa registrar observaciones de fenómenos naturales y recoger especímenes de objetos naturales. Significa además despojar de su carácter milagroso o sobrenatural a los sucesos que supuestamente lo son. El DRAE no contiene ninguna de estas dos acepciones, aunque la primera de ellas existe en español. Creo que no tenemos ningún término para referirnos a la práctica de bajarle los humos al milagrero o al telépata. "Naturalización", aplicado a la epistemología, parece una extensión de este segundo significado, porque la despoja de su especial estatuto.

Los filósofos han recomendado programas de naturalización en disciplinas que dependían de fundamentos desacreditados, $o$ indebidamente acreditados. En la ética, los deberes, los valores y los mandamientos eran fundados sobre la voluntad divina. Posteriormente lo fueron sobre la ley natural, que es el conjunto de los mandatos de Dios tal como éstos se manifiestan, supuestamente, en el supuesto orden natural. Espinosa trató de fundar la ética en el orden natural, y razonó que este orden era suficientemente autónomo y que, por lo tanto, poseía las propiedades de la providencia divina, pero que, desde luego, no hay providencia divina aparte del orden natural. Espinosa es un ejemplo de filósofo que se esforzó por naturalizar creencias cuyo fundamento no estaba desacreditado, sino indebidamente acreditado.

En el terreno de la ética se han llamado "naturalistas" las posiciones que trataban de sustentar la norma moral sobre teorías empíricas o, por extensión, sobre teorfas distintas de las morales. Por ello se ha denominado "falacia naturalista" todo intento de derivar un "debe" de un "es", esto es, de deducir logicamente un juicio de valor, o de deber o un imperativo de un conjunto de juicios sobre hechos. Mientras que, por extensión, comete la falacia naturalista incluso quien intenta fundar una ética sobre una teología, en un sentido más apropiado la comete quien intenta fundar un juicio de valor sobre tesis empíricas.

Se echa de ver, pues, que los proyectos naturalistas en ética no tienen, ni mucho menos, la intención de eliminar la norma moral. Por el contrario, pretenden que tenga toda la solidez que le pueda proporcionar un conocimiento más seguro, como lo es el que ofrece la ciencia acerca de la naturaleza, incluida la humana. Fueron los críticos de la falacia naturalista quienes padecieron la acusación de relativismo o de arbitrismo moral, porque la independencia de los juicios morales hace dificil, según muchos filosofos de la moral, argumentar sin peticiones de principio en favor de unos juicios mejor que de otros. 
En cambio, en epistemología son los naturalizadores quienes han sido objeto de acusaciones de relativismo, aunque algunos lo profesan de buena gana, porque la naturalización es ambigua. Unos la entienden como la eliminación de la disciplina en favor de otras, científicas, tales como la psicología, la historia o la sociología, con lo que renuncian a las normas epistemológicas. Otros creen mostrar que el valor de las normas es relativo a las comunidades que las usan. Y otros, a semejanza del naturalismo en moral, sólo aspiran a fundamentar estas normas en el conocimiento científico.

En el paralelismo que se advierte entre la naturalización de la ética y de la epistemología, no faltan quienes pretenden fundar la epistemología normativa en algo distinto del conocimiento científico. Tampoco faltan quienes piensan que, eliminada la epistemología, no sólo la suple el estudio científico de los procesos cognitivos humanos, sino que incluso los estudios literarios y humanísticos sobre la ciencia tienen un lugar interesante en sustitución de la epistemología. Así, los trabajos sobre el estilo literario de la ciencia, la retórica de la ciencia, etc.

En filosofla política es común distinguir entre Marx, marxianos y marxistas. Tengo la impresión de que en epistemología, también es obligatorio distinguir entre Kuhn, kuhnianos y kuhnistas. Kuhn y algunos seguidores de su secta han sido acusados de relativismo epistemológico. Aparte de la justicia de esta imputación a Kuhn, hay kuhnianos que pertenecen al grupo de los que han asumido los cargos y kuhnistas que defienden al maestro de interpretaciones desagradables, como la que conlleva la acusación de relativismo.

El programa fuerte de sociología de la ciencia es un caso muy notable de filiación kuhniana. Solís los adscribe a una variante del proyecto de naturalización de Quine, uno de cuyos ejecutores es Kuhn. Entienden que la naturalización implica el relativismo epistemológico o la desaparición de la epistemologla normativa, pero no es lo mismo una cosa que la otra. El relativismo sostiene que hay norma, y que depende su aceptabilidad de la comunidad que consideremos. Algunos relativistas trafican entre la valoración de las normas relativamente a las comunidades (las normas son válidas en la comunidad que las avala), y la simple descripción de qué normas son aceptadas en qué comunidades, como si no se pudiera decir que son buenas o malas. Esto implica que no hay normas, salvo como objetos empíricos.

Estas consideraciones históricas no determinarán quién es el legítimo propietario de la palabra «naturalización», pero más vale que las discusiones 
posteriores abusen de un punto de origen que de derivaciones semánticas peculiares o traídas de muy lejos.

En lo que resta del artículo discutiré la idea de naturalización de Quine y algunos de los argumentos que emplea para defender el proyecto de naturalización de la epistemología. A continuación, examinaré algunas propuestas que se acogen al programa de naturalización. Por último analizaré algunas de las maneras como se relacionan discursos normativos y discursos descriptivos, $y$ qué tiene de característico la relación entre estos discursos tal como se establece en la epistemología naturalizada.

No está claro si Quine ha tenido sucesivamente dos ideas distintas de lo que debería ser la naturalización de la epistemología o si sólo ha tenido una que ha desarrollado posteriormente. En "Epistemology Naturalized" (EN en adelante) identifica el impulso motriz de la epistemología con el ideal de fundar lógicamente la ciencia natural sobre la experiencia sensible. Esto es, deducir lógicamente los enunciados de la ciencia a partir de enunciados de observación y definir los términos de la ciencia a partir de términos que se refieran a la experiencia sensible. Pero las oraciones de la ciencia no se pueden probar lógicamente (ni siquiera contando con la teoría de conjuntos) a partir de oraciones observacionales. Tampoco se puede reconstruir el discurso de la ciencia en términos de observación, lógica y teorfa de conjuntos. Dado este fracaso en el plano de la teoría (doctrinal, tal como lo llama Quine) y en el del significado (conceptual), Quine propone estudiar cómo de hecho, a partir de la estimulación sensorial, se construye la teoría, esto es, según Quine, entregar "la carga epistemológica a la psicología", porque la tarea de establecer una relación de fundamentación entre experiencia sensible y teoría, objeto de la epistemologfa, se abandona en favor del estudio de la relación que de hecho hay, en nuestro sistema cognitivo, entre experiencia y teoría, y esta cuestión empírica se encomienda a la psicología. No a la sociología, ni a la historia, ni a la crítica literaria.

No ha faltado quien notara ${ }^{1}$ que Quine sólo produce una argumentación contra una manera de entender la epistemología: la que él presenta, que se

1 P. O'Gorman, «Quine's Epistemological Naturalism», Philosophical Studies, XXX, 1984 discute esta idea. 
remonta al empirismo clásico y, en su parte conceptual, intentó desarrollar Carnap en Der Logische Aufbau der Welt. En esta obra, Carnap pretendía "constituir" los conceptos de la ciencia a partir de la experiencia. Las limitaciones de la epistemología que Quine señala en $E N$, las encuentra en la Aufbau. Pero ésta es sólo una manera, entre otras razonables, de hacer epistemología. Según esta advertencia, serfa posible practicar la epistemología sin necesidad de estar incurso en uno de los capítulos de una ciencia empírica, como la psicología. Quedan muchas cosas fuera que se pueden abordar sin tomar en consideración ciencias empíricas.

Quine ha admitido esta objeción (o, simplemente, ha desarrollado sus ideas) y Pursuit of Truth concede un lugar a la epistemologia desligada de las ciencias que de ordinario llamamos «empíricas»:

En esta asombrosa mezcla de relaciones entre la estimulación sensorial y nuestra teoría científica del mundo, hay un segmento que podemos, gracias a Dios, separar y aclarar sin dedicarnos a la neurología, la psicología, la psicolingüística, la genética, o la historia. Es la parte donde la teorla se contrasta mediante la predicción ${ }^{2}$.

En diversas ocasiones ha caracterizado Quine este segmento de la epistemología como lógica aplicada, como poco más que lógica aplicada y como teoría estadística.

La naturalización, tal como Quine la defiende en su primer artículo, ha sido objetada aduciendo que no deja lugar al componente normativo que tiene la epistemología. Esta no puede limitarse a describir, sino que su papel legítimo es sancionar el conocimiento: ella es el semáforo del saber. Rorty y Putnam ${ }^{3}$, entre otros, han afirmado que, en el proyecto de naturalización, no hay un sitio para este aspecto normativo. Incidentalmente, es curioso que Putnam ${ }^{4}$ piense que no se puede, como él dice, naturalizar la razón, y por otro lado sea un crítico de quienes sostienen que, en moral, el naturalismo es una falacia. A. Goldman 5 , en cambio, piensa que existen proyectos de naturalización, los más valiosos

2 W.v. O. QUINE, Pursuit of Truth, Cambridge, Mass., Harvard U. P., 1990, pág. 1.

3 R. RORTY, Philosophy and the Mirror of Nature, Princeton, Princeton U. P., 1979, pág. 225; H. Putnam, Las Mil Caras del Realismo, Barcelona, Paidos, 1994, pág. 58 passim, p. ej.

4 H. Putnam, Razbn, Verdad e Historia, Madrid, Tecnos, Caps. 6 y 9, sobre hechos y valores, y en particular, pág. 133.

5 A. Goldman, Epistemology and Cognition, Cambridge, Mass., Harvard U. P., 1986, pág. 3. 
según él, que sí le conceden un lugar a lo normativo, pero que el proyecto de Quine no lo hace.

Quine ha respondido que la epistemología naturalizada sí concede un lugar a lo normativo. La epistemología, como cualquier ciencia empírica, es una ciencia teórica y descriptiva, pero también posee aplicaciones prácticas. El conocimiento teórico o empírico se puede convertir en una base de normas prácticas, tanto en epistemología como en física. Si sabemos, por ejemplo, que el cobre es un buen conductor eléctrico, entonces, podemos recomendarlo para la construcción de circuitos eléctricos, y si queremos evitar los cortocircuitos, debemos aislar los cables. Igualmente, si sabemos que todo conocimiento se origina en la estimulación sensible (principio del empirismo, que además según Quine es un hecho de la psicología) debemos rechazar el supuesto conocimiento alcanzado por medios telepáticos.

Para que la información que ofrece la epistemología se pueda convertir en la base de normas, hace falta especificar los fines que sirven. Quine menciona como fines principales de la ciencia el entendimiento, el control y modificación de la naturaleza. También es un fin la predicción, aunque ésta es importante por otros motivos.

Solís encuentra que el programa de Quine, tal como éste lo ha especificado o reformulado en Pursuit of Truth, retorna a "los problemas epistemológicos no naturalistas de toda la vida" ${ }^{6}$, porque "aunque su normativismo es de tipo instrumental, de manera que se torna descriptivo una vez que se ha explicitado el parámetro final, éste se describe como búsqueda de la verdad o de la eficiencia en el logro de la verdad y la predicción" ${ }^{7}$. Según Solís, para llevar a cabo el programa naturalista habría que naturalizar «la caracterización de la 'verdad' o la 'adecuación' o lo que sea de las teorías" ${ }^{8}$, pero eso no parece cosa fácil. Puesto que el problema de la epistemología, es, para Solís, saber qué es creído con justificación, la epistemología naturalizada debería proporcionar, así interpreto a Solís, una elucidación naturalista del concepto de creencia justificada, o del concepto de verdad o de adecuación "o lo que sea".

\footnotetext{
6 C. Solfs, Razones e Intereses, Barcelona, Paidos, 1994, pág. 69.

C. Souts, Id.

C. Solts, Id.
} 
Ahora bien, pedir la naturalización del concepto de verdad parece tan peregrino como pedir la del condicional o la de las fracciones. Pero este inconveniente en el argumento de Solís no afecta a su eficacia, porque tampoco va dirigido contra ninguna tesis de Quine. Si se concibe la verdad como un ascenso semántico, no parece ser muy informativo asegurar que la verdad es un objetivo de la ciencia. Decir que una oración es verdadera equivale a simplemente afirmarla. Los científicos desean saber qué oraciones pueden afirmar, pero ése es el problema de la creencia justificada, no el de la verdad.

El proyecto de naturalización de Quine contiene vaguedades u oscilaciones o desarrollos inesperados de puntos de vista expresados en EN. Para empezar, ciertamente $E N$ no parece dejar un lugar a la epistemología normativa, pero esa impresión del lector está desautorizada por las aclaraciones ulteriores de Quine. Algunos autores, como Roth y Haack, han señalado que en Quine hay dos sentidos distintos de "teoría" y de "ciencia"?

Haack pretende diagnosticar el origen de algunas tesis de Quine en un tráfico ilícito entre dos sentidos de "ciencia". Yo no me atrevo a hablar de diagnósticos, como si los de un achacoso intelectual fueran, cuando se trata de los escritos de uno de los más grandes filósofos del siglo. Pero creo que Haack tiene razón en que Quine concibe la ciencia de dos maneras diferentes. En mi opinión eso se debe a la herencia racionalista del Círculo de Viena.

En el positivismo lógico hay también una vacilación entre dos sentidos de ciencia. Por un lado, la ciencia es un hecho institucional. La ciencia es lo que entendemos ordinariamente por "ciencia", las imágenes del mundo, los sistemas de creencias, y quizá sus aplicaciones tecnológicas, que producen ciertas comunidades, en la actualidad institucionalizadas. Por otro lado, la ciencia es conocimiento racional, lo que incluye que esté justificado por la experiencia. En este sentido, la ciencia no es patrimonio de ninguna institución, sino un tipo de conocimiento, o el conocimiento, accesible a todos los humanos. La ciencia es conocimiento intersubjetivo, o intersubjetivamente compartible. De acuerdo con esto, es posible dar reglas de aplicación universal sobre lo que es ciencia, se puede dar un criterio de demarcación, con independencia de las prácticas de las instituciones o comunidades científicas.

9 P. A. ROTH, "Theories of Nature and the Nature of Theories", Mind, 89, 1980. S. HAACK, "The Two Faces of Quine's Naturalism», Synthese, 94, 1993. 
La razón de esto es que todos ellos creen en el progreso, son ilustrados. Creen que el producto de las instituciones cientificas, tal como se han desarrollado, ejemplifica bien el ideal del conocimiento racional. Algunos ilustrados creen que se podrían perder las instituciones que promueven el conocimiento racional, o que esas instituciones no necesariamente y no todo el tiempo son racionales. Orwell describe un mundo posible que, a pesar de haber pasado su fecha de caducidad en la ficción, es una amenaza.

Los positivistas lógicos propusieron una epistemología normativa, y en ella inclúan numerosas reglas y un criterio de cientificidad. Este criterio dictaminaba que sólo son científicos los enunciados confirmables empíricamente. La justificación que ofrecían del criterio combina las dos perspectivas aludidas del positivismo lógico sobre la ciencia. Cuando se les preguntaba si el propio criterio era un enunciado confirmable respondían que no. Ayer dice que el criterio debe ser considerado como una definición, aunque no totalmente arbitraria, porque un enunciado que no satisfaga el criterio no sería entendido en el sentido en que habitualmente se entienden los enunciados cientificos y de sentido común ${ }^{10}$. Hempel también afirma que el criterio empirista de significado no es un enunciado empírico. Pero tomarlo como una definición sería considerarlo en cierto modo arbitrario. Propone, pues, que se entienda el criterio como una elucidación del concepto de oración que forma una afirmación inteligible, y se acoge al tratamiento que da Carnap de la elucidación ("explication") ${ }^{11}$.

Esta actitud de los positivistas lógicos, que, según parece, Quine comparte, explica algo bien enigmático en su proyecto de naturalización de la epistemologia. No es verosímil su idea de un sujeto humano que recibe ciertas entradas sensoriales y luego produce una descripción del mundo. No existe ningún sujeto fisico humano que haya hecho semejante cosa. La ciencia no es la creación de ningún sujeto individual. Es una actividad y un producto sociales. De modo que la sociología de la ciencia debería tener un lugar prominente en la epistemologia naturalizada. Quine mismo ha reconocido factores sociales en la adquisición del conocimiento: existe lo que él llama "la presión hacia la objetividad",

10 A. J. AYER, Introducción de 1946 de Language, Truth and Logic, Victor Gollanz Ltd., Londres, 1967.

11 C. HeMPEl, "Problemas y Cambios en el Criterio Empirista de Significado», en A. J. Ayer, El Positivismo Lógico, FCE, México, 1965. 
de naturaleza social y existe el llamado "principio de caridad». Consiste éste en el compromiso metodológico de interpretar pro bono las emisiones lingüísticas de los demás. Esto es, en atribuirles racionalidad mientras sea posible, en el sentido de la parsimonia de la teoría del comportamiento de esos sujetos ${ }^{12}$. Éste podría ser el principio básico de la hermenéutica, pero sólo si no la consideramos como una ciencia histórica. Vega ha mostrado que el principio de caridad tiene una estructura social. Sus trabajos sobre historia de la lógica medieval ponen de manifiesto que este principio se desglosa en una variedad de actitudes permitidas respecto a los textos académicos. No es lo mismo interpretar la Sagrada Escritura que una obra de Aristóteles o que un comentario. El principio de caridad, en cambio, tal como lo presenta Quine, es democrático: no debemos atribuit errores de lógica o de percepción a nadie mientras sea razonablemente económico no hacerlo, pero no hay nadie privilegiado. En la versión no democrática estarían privilegiados los practicantes de las disciplinas cientificas institucionales.

Quine claramente defiende la versión democrática, porque todos los humanos son estimulados de la misma manera por los cambios físicos de su entorno y no hay motivos para suponer de antemano que lo más elemental de la lógica es flagrantemente ignorado ${ }^{13}$.

Algún otro autor, como Davidson ${ }^{14}$, por citar sólo un ejemplo, piensa, dándole más alcance al principio de caridad, que la atribución de racionalidad es un supuesto básico de la interpretación de la conducta verbal, e incluso de la explicación, desde cierto punto de vista, de la conducta humana. Estas explicaciones, llamadas intencionales, se basan en la atribución de creencias y deseos, y sólo podemos atribuirlos si suponemos que el sujeto tiene cierto grado de coherencia. $\mathrm{O}$, dicho metodológicamente, si atribuir creencias y deseos no exige un conjunto de hipótesis demasiado abultado. En el extremo, puede ser más complicado considerar lingüísticas las emisiones de un organismo que tomarlas como un simple muestrario de grunidos.

12 El principio de caridad exige según QUINE no atribuir errores groseros de percepción ni de lógica mientras sea más económico no atribuirlos.

${ }_{13}$ Sin embargo, véase A. LuRIA, Cognitive Development, Cambridge, Mass., Harvard U. P. 1976.

14 D. DAvidson, Inquiries into Truth and Interpretation, Oxford, Clarendon, 1984, pág. 137. 
Tampoco estos autores han tenido en cuenta que esa atribución de racionalidad está estructurada por la autoridad. Dennett relata en "Why You Can't Make a Computer that Feels Pain" ${ }^{15}$ cómo las propiedades anestésicas del curare no fueron cuestionadas hasta que un médico fue intervenido quirúrgicamente bajo los efectos del curare. Las anteriores quejas de los pacientes no fueron tomadas en consideración por la profesión médica. Y eso en un tema en el que, según algunos filósofos de la mente, somos la autoridad incorregible: las afecciones de nuestra sensibilidad, y en particular el dolor. El ejemplo muestra que incluso la aceptabilidad de los informes de observación más sencillos está organizada por factores sociales poderosos.

A pesar de esto, el encargo a la psicología del trabajo epistemológico que propone $E N$ ha sido asumido por diversos epistemólogos y psicólogos. Han encontrado en la psicología cognitiva fuentes de iluminación que proyectar sobre problemas epistemológicos. Ahora bien, podemos entender por psicología cognitiva dos cosas: una, la psicologia que se ocupa del conocimiento, y, otra, la corriente, dentro de ésta, que monopoliza esta denominación en nombre de la escuela que se suele llamar "cognitiva». En este enfoque, las teorías se permiten el uso de lenguaje intencional, de modo semejante a como se usa en el lenguaje ordinario, aunque con algunas restricciones empíricas y formales. Se ha pretendido hacer aportaciones a la naturalización de la epistemología desde la psicología cognitiva en este sentido más estrecho y también desde otras teorías psicológicas sobre el conocimiento.

La percepción, el reconocimiento de formas, el aprendizaje y la formación de conceptos, el razonamiento deductivo, el razonamiento inductivo, la formación de hipótesis, la psicología del testimonio, la toma de decisiones, la memoria, la resolución de problemas son temas de la psicología cognitiva que diversos epistemólogos han empleado, con éxito variable, en la obra de naturalizar la epistemología.

De acuerdo con Kuhn, por ejemplo, existen dificultades de comunicación entre cientificos de tradiciones diferentes, y una de las causas de estos problemas está en el modo como el aparato cognitivo humano aprende y forma conceptos. En estos experimentos resulta que muchas veces lo que ha aprendido o 
formado el sujeto no es una regla que pueda explicitar verbalmente. Puede darse el caso de que otro sujeto haya aprendido otro juego de conceptos para un conjunto de muestras igual o coincidente sólo en parte. Una dificultad añadida, de paso, puede ser que ambos sujetos empleen un vocabulario semejante, y empleen las mismas palabras para conceptos distintos. Puede, pues, haber desacuerdo sobre la denotación de un término común a los vocabularios de ambos sujetos. Puede también haber desacuerdos sobre la sensatez de segmentar las muestras de una manera $u$ otra. Carecer de reglas que expliciten qué propiedades tienen que tener las muestras para ser instancias de los conceptos dificulta la discusión de los desacuerdos.

Si esa dificultad fuera una imposibilidad psicológica, tendríamos un resultado empírico que afecta gravemente a la epistemología. Podría haber tradiciones científicas separadas por una barrera de incomunicación de este estilo. Y entonces podría ocurrir que unos no pudieran entender los enunciados observacionales producidos en la otra tradición. Si estos enunciados fueran considerados decisivos para la contrastación de una teoría, no habría forma de que los científicos de la otra tradición lo apreciaran convenientemente. Pero todo esto es en vano. El mismo Kuhn asegura que no hay tales imposibilidades psicológicas, y que los científicos en ocasiones y los historiadores de la ciencia casi siempre, se ocupan de la traducción de lenguajes de tradiciones científicas ajenas. Kuhn produce, a la vista de esto, unos argumentos lingüisticos sobre las dificultades de la traducción sujetos a graves dificultades que no vamos a discutir aquí ${ }^{16}$.

Hanson, por su parte, también ha sacado partido de algunos hechos sobre la psicología de la percepción para cuestionar la viabilidad de hacer experimentos cruciales, esto es, experimentos que decidan entre teorías contrapuestas. El experimento, para ser crucial, ha de poder ser descrito en términos inteligibles para las tradiciones en que se formulan las teorias rivales, y Kuhn señala que eso puede ser imposible. Hanson indicó que puede haber divergencias en la percepción de las mismas muestras. Los experimentos de la psicología de la Gestalt que Hanson aduce indican que una persona puede poseer los mismos conceptos que otra y, sin embargo, tomar las mismas muestras como instancias de diferentes conceptos. Son casos de la diferencia figura-fondo, de los que son ejemplos el pato-conejo o la vieja-joven. Que un sujeto vea siempre,

16 J. Armero, «Los Argumentos Lingüísticos de Kuhn», Endoxa, n. 9, págs. 125-137. 
digamos, el pato en vez del conejo, puede deberse a factores de su entrenamiento o de la situación en que los encuentra. Si esos factores tuvieran un efecto tan tenaz sobre la percepción de los científicos de tradiciones distintas, sería dificil zanjar los desacuerdos observacionales entre tradiciones científicas separadas por su forma de ver. En este caso, decir que diferentes tradiciones comportan diferentes visiones del mundo es bastante literal. Se ha dicho que sujetos que vean cosas diferentes en los dibujos de los ejemplos, con todo, puestos a la tarea de copiarlos, harán copias semejantes. Esto, sin embargo, es dudoso, y podría ser objeto de un experimento. Si lo que se almacena en la memoria (caso de que la copia se haga sin modelo) o lo que guía la atención (caso de que la copia se haga con modelo) no son los rasgos elementales, sino la configuración percibida, entonces es conjeturable que las copias sean diferentes cuando los sujetos ven el pato o ven el conejo.

En la psicologia cognitiva se distinguen dos direcciones en el procesamiento de información que media entre los estímulos sensoriales y la formación de conceptos y de juicios. Hay una dirección ascendente y otra descendente. La primera procede desde la estimulación sensorial hasta los juicios y conceptos. Se la denomina kascendente" porque durante mucho tiempo, doctrinas epistemológicas influyentes han considerado superior el juicio y la conceptualización e inferior la sensibilidad, porque ésta es compartida con los animales. La otra dirección, descendente, procede desde los conceptos previamente formados que, ante estimulaciones sensoriales dadas, afectan a la formación de los perceptos. Esta dirección ha sido desconocida hasta que la estudió la escuela de la Gestalt, que ha mostrado diversos efectos de la percepción ilustrativos de ambas direcciones del procesamiento.

Aparte de efectos como el del pato-conejo, que están influidos por factores educables, la escuela de la Gestalt ha trabajado con efectos que son universales para la especie humana. Los factores innatos del procesamiento descendente ponen limitaciones al modo como pueden afectar a ese procesamiento las creencias adquiridas. Varios efectos descritos por los psicólogos de la Gestalt se siguen presentando en nuestra percepción a pesar de nuestro conocimiento de los mismos. Esto muestra que el procesamiento descendente no tiene un carácter holista, esto es, que no todo lo que conocemos puede afectar a nuestra percepción ${ }^{17}$.

17 Z. PYLYshYN, Computation and Cognition, Cambridge, Mass., MIT, 1984. 
La psicología del testimonio es pertinente para el problema epistemológico de corroborar el acontecer de hechos singulares, e incluso de regularidades. En su discusión de los milagros ya Hume advertía que antes puede mentir la Reina de Inglaterra que ocurrir una violación de las leyes naturales. De modo que, cuando Hume se enfrentaba a la elección entre un testimonio sobre un hecho singular y una ley natural manifestaba una preferencia epistemológica basada en cuestiones de hecho.

En astronomía es un lugar común contar con el sesgo de los observadores individuales para corregir el valor de sus informes observacionales, y ello forma parte de la metodología de esta ciencia. Descartes aducía las propensiones al error, ocasionales o persistentes, en la percepción como uno de sus argumentos para adjudicar un bajo estatus epistemológico a los informes de los sentidos, en comparación con el alto estatus que concedía a la razón.

En la sociologia de la ciencia se intenta explicar el fraude que ocasionalmente se produce en los resultados empíricos, y esa explicación invoca factores sociales, como la competitividad y la presión que sufren los cientificos, pero esas explicaciones no son nada si no se presuponen algunas cosas sobre la psicologia del investigador particular que comete el fraude, de suerte que las explicaciones del fraude suelen aportar datos biográficos del malhechor ${ }^{18}$.

En las discusiones sobre racionalidad también se han introducido factores naturalizadores, y uno de ellos ha sido cómo el modo de operación de la memoria humana interviene en el comportamiento racional y qué limitaciones impone sobre él. La memoria a largo plazo no se renueva hasta el punto de que las informaciones contenidas en ella alcancen una plena compatibilidad con las informaciones adquiridas posteriormente. Es decir, la memoria a largo plazo contiene informaciones contradictorias. A. Goldman piensa que este hecho pone en cuestión una de las reglas metodológicas que propusieron los positivistas lógicos. Se trata de la regla de la "evidencia disponible total». Sin embargo, la información disponible a la que se refiere la regla de Hempel no es la que contiene en su memoria un sujeto, sino aquélla de la que dispone la comunidad cientifica.

Los hechos que descubre la psicología sólo parecen tener un alcance para la toma individual de decisiones, o para la racionalidad de las creencias de indi-

18 A. КоHN, Falsos Profetas, Madrid, Pirámide, 1988. 
viduos particulares. Pero la ciencia es una empresa comunitaria que cuenta con medios de representación de la información no limitados a las memorias individuales. Si hemos de encontrar limitaciones a la regla de la evidencia total, debe ser en los modos de representación y de procesamiento sociales de la información, los cuales afectan de forma muy notable a los hábitos individuales de razonamiento, como mostró Luria en su tiempo ${ }^{19}$.

Los estudios psicológicos sobre el razonamiento han dado que pensar sobre si los sujetos humanos se atienen en todas las ocasiones a las reglas de inferencia de la lógica clásica, ni siquiera en los razonamientos que parecen requerir estas reglas. Sin embargo, habría además que mostrar que estos efectos están presentes en el razonamiento científico para que los estudios empíricos sobre el razonamiento deductivo puedan aportar algo a la naturalización de la epistemología. Y no parece que en la historia de la ciencia haya ejemplos de errores lógicos que hayan persistido después de la crítica.

En el razonamiento deductivo, como en el inductivo, cualquier sistema de reglas no clásico cuyo empleo continuado se detectara se convertiría rápidamente en objeto de estudio de la lógica, y daría lugar a la creación de un sistema formal. De modo que, más que la naturalización de la lógica ocurriría una logicización de la psicología.

Aunque practicada por seres humanos individuales, es evidente que la ciencia es una empresa social, y en la sociología y la antropología se han originado proyectos de naturalización. La sociología se ocupa de la ciencia desde dos perspectivas que han sido denominadas "programa débil» y "programa fuerte". El primero, aunque más antiguo, ha recibido esa denominación por contraposición con el segundo. Se puede decir con bastante justicia que el más destacado practicante $e$ iniciador del programa débil fue Merton. Este se interesaba por cuestiones tales como el reclutamiento social de las vocaciones científicas, los factores sociales que intervienen en la elección de campos de investigación y en su promoción, el impulso y la oposición que pueden ofrecer a la ciencia los grupos sociales, el papel que desempeñan otras formaciones ideológicas, la estructura de las comunidades cientificas, etc. Dejaba fuera de la jurisdicción

19 A. LuRIA, Cognitive Development, Cambridge, Mass., Harvard U. P., 1976. 
de la sociología de la ciencia el valor epistemológico de las producciones y de los métodos científicos, y tampoco se ocupaba de por qué unas teorías son preferidas a otras en el seno de las comunidades científicas. Es por esta limitación de objetivos por lo que su programa es denominado «débil».

Por el contrario, el programa fuerte pretende explicar, además, por qué son aceptadas unas $\mathrm{u}$ otras teorías en las comunidades científicas, por qué son empleados unos u otros métodos e incluso qué papel ideológico tiene hablar sobre métodos en la literatura científica.

En la época en que escribía Merton estaba bien asentada la distinción entre contexto de justificación y contexto de descubrimiento. En los estudios sobre la ciencia, los filósofos se ocupaban del contexto de justificación y la sociología se mantenía en el contexto de descubrimiento. La distinción fue recusada por filósofos historiadores como Hanson y Kuhn, porque según ellos, en el contexto de justificación intervienen elementos que se habían considerado propios del contexto de descubrimiento. Los sociólogos del programa fuerte comparten plenamente esta opinión.

La distinción va acompañada por la que hay entre estudios internalistas y externalistas de la ciencia, o factores internos y externos del proceso científico, o factores técnicos o intelectuales y factores sociales. Un estudio internalista en historia de la ciencia intenta mostrar los avatares de las teorías como el producto de consideraciones disciplinares en el período histórico de que se trate. Un estudio externalista se ocupa de hechos sociales relativos a la disciplina, a la comunidad que la desarrolla y al contexto social más amplio que puede afectar a la ciencia o ser afectado por ella.

Los sociólogos del programa débil créan que el enfoque más razonable para la sociología de la ciencia es el externalista, porque la esfera técnica e intelectual tiene autonomía. Otros sociólogos han propuesto investigar las relaciones entre elementos externos $e$ internos. Pero los seguidores del programa fuerte han objetado que creer en esas relaciones equivale a creer en la distinción entre una y otra clase de elementos. Y ellos piensan que la distinción forma parte de la ideología o la mitología de la ciencia. La distinción entre enfoque internalista y externalista debe ser estudiada como un objeto sociológico, como el resto de la actividad científica y sus circunstancias. ${ }^{20}$ Practican lo que se 
podría considerar un gran externalismo que se injiere en lo que tradicionalemnte se tomó como perteneciente a la esfera interna de la ciencia.

Los historiadores de la ciencia y los sociólogos del programa fuerte se plantean el problema del cambio científico y de por qué unas teorías son preferidas a otras en situaciones históricas. Los filósofos de la ciencia tradicionales, en la escasa medida en que se han ocupado de estos problemas, han dado una respuesta a esta cuestión que consiste en sugerir que el destino de las teorlas depende de buenas o de malas razones, de acuerdo con un patrón epistemológico. Si las razones son buenas, entonces la epistemología debe dar cuenta de estos sucesos históricos, y si son malas, entonces compete a la psicología, la sociología o la historia explicar por qué se produjo ese desvío de lo que se debería haber hecho ${ }^{21}$. En conjunto, de todas formas, la ciencia es una empresa racional y, por lo tanto, su desarrollo se atendrá a las normas epistemológicas. Popper ha coloreado este punto de vista con su famosa doctrina de los tres mundos. La ciencia es una empresa del tercer mundo, el de las relaciones lógicas y racionales entre ideas y entre teorías. Pero también la ciencia es un hecho institucional, perteneciente al segundo mundo, o de los hechos sociales y psicológicos. Si lo que ocurre en el segundo mundo se desvía de lo que ocurre en el tercero, el filósofo de la ciencia no puede sino constatar esa desventura y dejar que indaguen sus causas los científicos sociales. $\mathrm{Si}$, por el contrario, todo va bien, entonces la epistemologia da cuenta de los sucesos institucionales o, dirían los positivistas lógicos, es vindicada ${ }^{22}$. por éstos. Cuando Popper y los positivistas lógicos se dedican a la filosofia de la ciencia, creen que su empresa tiene sentido porque, en conjunto, la ciencia del segundo mundo se atiene a la ciencia del tercer mundo, o que su filosofía de la ciencia es vindicada por la historia.

Hanson, Kuhn, y otros después, creen haber mostrado que eso no ocurre, que el desarrollo de la ciencia no puede ser explicado como si respetara o desenvolviera alguna epistemología o algún conjunto de reglas metodológicas. Feyerabend emitió su famoso juicio de "Todo vale" refiriéndose a qué reglas metodológicas instancia la historia de la ciencia.

21 H. Reichenbach, La Filosofla Cientifica, México, F.C.E., 1955, pág. 127. No veda, sin embargo, que estas ciencias sociales se ocupen de la buena ciencia.

22 H. FEIGL, "The Origin and Spirit of Logical Positivism», en P. Achinstein y S. Barker (eds.), The Legacy of Logical Positivism, Baltimore, John Hopkins, 1969, p. 11, alude al concepto de vindicación. 
Algunos autores que comparten puntos de vista con el programa fuerte, como Latour, no se pronuncian sobre el valor de las reglas metodológicas $\mathrm{ni}$ sobre el de los productos de la ciencia. Pero sin duda piensan que no es muy explicativo de la actividad de los científicos tratar de descubrir cuáles son las reglas metodológicas, ya sean las que proclaman o las que efectivamente siguen, si es que hay diferencias. Más bien, el discurso sobre reglas deberla ser explicado ${ }^{23}$.

Así, pues, por un lado tenemos la clásica opinión de que, cuando en la ciencia las cosas van bien, es necesario (y quizá bastante) el análisis lógico, y cuando no es así hay que echar mano de la historia o de la psicología para explicar lo sucedido. El llamado por Laudan «supuesto de arracionalidad» llega al extremo de mantener que "la sociologia del conocimiento puede aventurarse a explicar las creencias si y solo si esas creencias no se pueden explicar en términos de sus méritos racionales" ${ }^{24}$. Pero ésta es una exigencia poco razonable. Nada impide que, además de lógica de la ciencia, se haga sociología incluso de la ciencia correctamente realizada. Por otro lado, el programa fuerte sostiene que es mejor olvidarse de la lógica y la metodología y acometer la explicación sociológica del cambio científico.

Algo muy semejante al supuesto de arracionalidad se encuentra también en un territorio aparentemente muy distinto. Ryle decla que la explicación de la conducta que ofrece la psicología sólo debe ser invocada cuando en la conducta algo va mal. Cuando las cosas ocurren como de ordinario, basta con las explicaciones del sentido común, que, de paso, son explicaciones intencionales.

También Chomsky piensa que la conducta verbal, cuando es correcta, se debe explicar mediante la teorfa de la competencia del lenguaje de que se trate, mientras que una gran variedad de incorrecciones se explican empleando la teoría de la actuación, que es psicológica. Chomsky afirma que existe un órgano cerebral especializado en el conocimiento lingülstico, y que la conducta verbal es producto de la actividad de ese órgano y de algunos otros. Los errores y limitaciones de la conducta se deben a limitaciones de la capacidad de procesamiento del módulo lingülstico y de otros módulos cerebrales. Pero Chomsky no parece mantener una especie de principio de arracionalidad que prohíba a la psicologia

23 Véanse, por ejemplo, los artículos contenidos en el libro editado por J. SCHUSTER y R. YeO, The Politics and Rhetoric of Scientific Method Dordrecht, Reidel, 1986.

24 L. LAUDAN, Op. cit., pág. 201, en cursiva en el original. 
ocuparse del comportamiento lingüístico correcto. La psicología puede legítimamente tratar de descubrir cuáles son los mecanismos del módulo linguíístico, aunque en este cometido debe estar guiada por la teoría de la competencia.

Cuando jugamos al ajedrez contra una máquina tratamos de explicar y prever su conducta en los términos intencionales ordinarios, y le atribuimos deseos y expectativas. Suponemos que razona disponiendo medios para lograr sus fines, que no comete errores elementales de lógica y que sigue las reglas del ajedrez. El resultado de la partida lo juzgamos, en lo que podríamos llamar contexto de justificación, de acuerdo con las reglas del ajedrez. Pero sería absurdo suponer que no hay programas ni circuitos responsables de la actuación de la máquina.

En la discusión de estos casos se emplean varias distinciones emparentadas pero diferentes: las que hay entre contexto de justificación y de descubrimiento, entre interno y externo, entre competencia y actuación y entre nivel intencional y de diseño y físico.

Cuando el programa fuerte se propone ofrecer un estudio causal en términos sociológicos de por qué ciertas cosas son creídas, tiene pocas posibilidades de mantenerse fiel a la promesa. Lo más que ofrece son explicaciones intencionales en términos de intereses y de cómo ciertas creencias apoyan bien esos intereses bien otras creencias que se usan en apoyo de los mismos. Tan intencionales como la explicación de una creencia diciendo que quien la sustenta lo hace porque tiene buenas razones.

Si decimos que el pequefio Hans se abstuvo de mover el caballo por temor de su padre, que asistía como espectador a la partida, la explicación es intencional, tanto como si decimos que no lo movió porque tenía sobre la pieza una clavada del alfil contrario y temía esa posición. En cambio, si decimos que no lo movió porque el árbitro le sujetó el brazo, la explicación es causal, tanto como si decimos que no lo movió porque sus neuronas motoras no se dispararon.

Si explicamos la conducta de Hans por el temor al padre tenemos una explicación intencional, pero externalista, y si la explicamos a la luz de las creencias de Hans sobre la posición, la explicación es internalista. La remota base que puede tener el supuesto de arracionalidad es que las explicaciones internalistas no necesitan muchos elementos de juicio empíricos. La jugada de Hans puede haber sido mala o buena, pero la propia posición y la jugada de Hans nos suministran casi toda (en la práctica toda) la información que necesitamos para atribuir las creencias y los intereses involucrados en la explicación. 
Si la jugada fue mala, basta con que podamos razonablemente suponer que Hans la creía buena. Si la jugada es absurda necesitamos información adicional para dar una explicación externalista: temía a su padre, o estaba jugando a ciegas y la posición se borró de su memoria. A veces hasta renunciamos a la explicación: todo gran maestro ha cometido algún error de novato.

Las explicaciones internalistas invocan la competencia del agente, pero más bien la suponen que confirman su existencia por vlas independientes. Si un mono hace una jugada de ajedrez correcta, el supuesto de la competencia será cuestionado y se requerirá evidencia independiente de que posee la habilidad. Pero no hace falta suponer que hay un órgano o un módulo de la competencia. Si creemos que hay tal órgano, entonces decir que invocamos la competencia en una explicación es ambiguo. Podemos estar dando una genuina explicación internalista o una explicación en términos del órgano que realiza físicamente la capacidad en cuestión. El problema de qué diríamos en semejante caso es en buena parte terminológico. La explicación no es externalista, porque no alude a factores ajenos a la competencia, pero ésta no es descrita como un sistema de reglas, que es la forma como la competencia aparece cuando se la emplea en explicaciones internalistas. Esto sería tanto como haber naturalizado la competencia. Por otro lado, un aspecto del problema no es terminológico y necesita alguna aclaración. La competencia que invocamos al explicar una buena jugada debería ser la que está instanciada en el cerebro del jugador. Sin embargo, en la mayoría de las explicaciones que aluden a la competencia no se comprueba esta circunstancia. Una competencia no instanciada en un cerebro no puede explicar nada, salvo comportamientos idealizados. La competencia de un hablante-oyente ideal solo aproximadamente explica la conducta lingüistica de hablantes-oyentes reales.

Naturalmente, que la jugada sea buena o mala y en qué grado es independiente de cualesquiera explicaciones que tengamos de por qué Hans la hizo. Podemos explicar desde diferentes perspectivas por qué la hizo, y una de estas perspectivas presupone que atribuimos a Hans la creencia en que era buena, y si compartimos la opinión de que es buena no solemos necesitar más. Así, algunas de estas explicaciones presupone una opinión por parte de quien explica sobre la bondad del movimiento, y la suposición de que quien explica posee la competencia en el juego. Pero el problema de si es buena o mala la jugada no tiene nada que ver con nada de esto, y en la discusión solo es legítimo aducir las reglas del juego. 
El programa fuerte se propone explicar las creencias con imparcialidad respecto a su valor de verdad y respecto a la justificación que poseen. La expresión correcta para que la propuesta sea sensata es usin pronunciarse respecto a su valor de verdad ni a su grado de justificación". Sin embargo, esto deja un amplio campo al género de explicaciones que apelan a las buenas razones y a la estructura de las buenas argumentaciones. Si el programa fuerte sugiere la descalificación de este tipo de explicaciones, se encuentra en la posición del psicólogo que pretendiera descalificar la tarea del lingüista porque la psicología se ocupa de la conducta verbal con imparcialidad respecto a la corrección o incorrección de las emisiones verbales.

El programa fuerte se propone también ofrecer el mismo tipo de causas para las creencias (tenidas por) verdaderas o falsas. Sin embargo, es muy posible que las creencias justificadas no tengan las mismas explicaciones (o incluso causas) que las injustificadas. En el caso de las oraciones gramaticalmente correctas es posible que éstas estén generadas por un módulo cerebral lingüístico y las incorrectas requieran la intervención de algún otro módulo. Hay oraciones a las que asentimos solo bajo muy restringidos marcos de estimulación, y sostener las creencias correspondientes ha de explicarse de una manera específica, no comparable a la creencia en extraterrestres, al menos en la mayoría de los casos. Es posible que podamos evaluar la fiabilidad y otras cualidades epistémicas de los procesos cognitivos, como intenta Goldman. Pero aunque no se pudiera, la trama de la justificación posee un orden lógico que vale la pena conocer, y cuyo rendimiento a la hora de explicar la conducta de la comunidad cientifica es bien notable. 